\title{
Can Pornography be Addictive? An fMRI Study of Men Seeking Treatment for Problematic Pornography Use
}

\author{
Mateusz Gola*, I,2 , Małgorzata Wordecha ${ }^{2}$, Guillaume Sescousse ${ }^{3}$, Michał Lew-Starowicz ${ }^{4}$, Bartosz Kossowski ${ }^{5}$, \\ Marek Wypych ${ }^{5}$, Scott Makeig', Marc N Potenza ${ }^{6,7,8}$ and Artur Marchewka \\ 'Swartz Center for Computational Neuroscience, Institute for Neural Computations, University of California San Diego, San Diego, CA, USA; \\ ${ }^{2}$ Clinical Neuroscience Laboratory, Institute of Psychology, Polish Academy of Sciences, Warsaw, Poland; ${ }^{3}$ Donders Institute for Brain, Cognition and \\ Behaviour, Radboud University, Nijmegen, The Netherlands; ${ }^{4}$ III Department of Psychiatry, Institute of Psychiatry and Neurology, Warsaw, Poland; \\ ${ }^{5}$ Laboratory of Brain Imaging, Neurobiology Center, Nencki Institute of Experimental Biology of Polish Academy of Sciences, Warsaw, Poland; \\ ${ }^{6}$ Department of Psychiatry, Child Study Center and the National Center on Addiction and Substance Abuse, Yale School of Medicine, New Haven, \\ CT, USA; ' Department of Neurobiology, Child Study Center and the National Center on Addiction and Substance Abuse, Yale School of Medicine, \\ New Haven, CT, USA; ${ }^{8}$ Connecticut Mental Health Center, New Haven, CT, USA
}

Pornography consumption is highly prevalent, particularly among young adult males. For some individuals, problematic pornography use (PPU) is a reason for seeking treatment. Despite the pervasiveness of pornography, PPU appears under-investigated, including with respect to the underlying neural mechanisms. Using functional magnetic resonance imaging (fMRI), we examined ventral striatal responses to erotic and monetary stimuli, disentangling cue-related 'wanting' from reward-related 'liking' among 28 heterosexual males seeking treatment for PPU and 24 heterosexual males without PPU. Subjects engaged in an incentive delay task in the scanner, in which they received erotic or monetary rewards preceded by predictive cues. Blood-oxygen-level-dependent responses to erotic and monetary cues were analyzed and examined with respect to self-reported data on sexual activity collected over the 2 preceding months. Men with and without PPU differed in their striatal responses to cues predicting erotic pictures but not in their responses to erotic pictures. PPU subjects when compared with control subjects showed increased activation of ventral striatum specifically for cues predicting erotic pictures but not for cues predicting monetary gains. Relative sensitivity to cues predicting erotic pictures vs monetary gains was significantly related to the increased behavioral motivation to view erotic images (suggestive of higher 'wanting'), severity of PPU, amount of pornography use per week, and number of weekly masturbations. Our findings suggest that, similar to what is observed in substance and gambling addictions, the neural and behavioral mechanisms associated with the anticipatory processing of cues specifically predicting erotic rewards relate importantly to clinically relevant features of PPU. These findings suggest that PPU may represent a behavioral addiction and that interventions helpful in targeting behavioral and substance addictions warrant consideration for adaptation and use in helping men with PPU.

Neuropsychopharmacology (2017) 42, 202 I-203I; doi:I0.1038/npp.2017.78; published online 17 May 2017

\section{INTRODUCTION}

Pornography consumption has become highly prevalent, in part given Internet availability (Luscombe, 2016). Approximately $70 \%$ of males and $20 \%$ of females aged $18-30$ years use pornography weekly (Hald, 2006). Among teenagers aged $<18$ years, $90 \%$ of boys and $60 \%$ of girls have used Internet pornography (Sabina et al, 2008), with $12 \%$ of children having onset of regular consumption below age 12 years (Opinium Research, 2014). For most people, pornography viewing is a form of entertainment, but for some individuals problematic pornography use (PPU)

\footnotetext{
*Correspondence: Dr M Gola, Swartz Center for Computational Neuroscience, Institute for Neural Computations, University of California San Diego, 9500 Gilman Drive, San Diego, CA $92093-$ 0559, USA, Tel: 858500 2554/858 822 7543, E-mail: mgola@ucsd.edu Received 25 January 2017; revised 27 March 2017; accepted 7 April 2017; accepted article preview online 14 April 2017
}

accompanied by excessive masturbation promotes seeking of treatment (Gola et al, 2016a). Such observations raise multiple scientifically and clinically important questions, including with respect to brain mechanisms related to PPU and their relationships to clinically relevant measures. Given the negative health measures associated with compulsive sexual behavior (CSB) broadly (eg, childhood sexual trauma and posttraumatic stress disorder; Smith et al, 2014), more research is needed in order to better understand specific forms of CSB such as PPU and develop improved intervention strategies (Kafka, 2014; Kor et al, 2013; Kraus et al, 2016).

The existence and clinical utility of non-substance or behavioral addictions has been debated, with gambling disorder currently being the sole non-substance disorder classified together with substance-use disorders in DSM-5 (American Psychiatric Association, 2013; Holden, 2001). Although a field trial for hypersexual disorder (Kafka, 2010) was conducted, neither this condition or related behaviors 
such as PPU were included in DSM-5, in part given the relative paucity of data on these behaviors or conditions (Kafka, 2014; Krueger, 2016; Reid et al, 2012). Whether excessive and problematic patterns of sexual behavior are best conceptualized within obsessive-compulsive disorder (OCD), impulse-control disorder (ICD), behavioral addiction or other frameworks has been debated (Kafka, 2014; Kor et al, 2013; Kraus et al, 2016). A recent case series reported that low dose $(20 \mathrm{mg} /$ day) of paroxetine treatment (found to be successful in treating OCD; Stein et al, 2007) led to reductions in anxiety and severity of PPU (Gola and Potenza, 2016). Additionally, naltrexone treatment (found to be successful in alcohol use (Maisel et al, 2013) and gambling disorders (Yip and Potenza, 2014) may be helpful for individuals with PPU (Bostwick and Bucci, 2008; Kraus et al, 2015). As naltrexone has been proposed to reduce craving through modulating activity in mesolimbic structures (Thompson et al, 2000), the ventral striatum may contribute importantly to CSBs, including PPU. Recent MRI studies of men support this hypothesis. Among non-problematic pornography users, an inverse relationship between right caudate volume and frequency of pornography consumption was observed (Kühn and Gallinat, 2014). Increased bloodoxygen-level-dependent (BOLD) responses in the ventral striatum were observed in response to preferred sexual pictures when compared with non-preferred ones, and this activity positively correlated with scores on the Internet Addiction Test Modified for Cybersex (Brand et al, 2016). Men with CSB (meeting criteria for hypersexual disorder; Kafka, 2010) as compared with those without (comparison subjects (CSubs)) demonstrated increased striatal reactivity for sexually explicit videos (Voon et al, 2014) and decreased functional connectivity between the ventral striatum and prefrontal cortex (Klucken et al, 2016). These findings suggest similarities between CSB and addictions.

A prominent model of addiction, the incentive salience theory (IST; (Berridge, 2012; Robinson and Berridge, 1993; Robinson et al, 2015) posits that wanting becomes dissociated from liking. The latter is hypothesized to be linked to the experienced value of the reward and the former to its anticipated value (Robinson et al, 2015). 'Wanting' is typically evoked by predictive cues associated with reward through Pavlovian learning (Berridge, 2012). Learned cues (conditional stimuli) related to addiction acquire incentive salience, reflected in increased BOLD response in the ventral striatum and increased motivated behavior (ie, shorter reaction times (RTs; Berridge, 2012). According to the IST, and consistent with observations in substance addictions and gambling disorder (Robinson et al, 2015; Sescousse et al, 2013), increased anticipatory 'wanting' is dissociated from experienced 'liking' in addiction. If PPU share mechanisms with addictions, we anticipate seeing increased BOLD response in the ventral striatum specifically for cues signaling erotic pictures followed by higher motivation to obtain them (measured as shorter RTs) in individuals with PPU compared with CSubs. Increased 'wanting' should be unrelated to measures of 'liking' in PPU subjects but not in CSubs.

The current study sought to extend prior studies by examining the neural correlates of sexual and non-sexual incentives in men seeking treatment for PPU and men without PPU. We further sought to relate the brain activations to clinically relevant features of PPU. No prior neuroimaging studies have examined individuals seeking treatment for PPU. Additionally, as it is important to investigate possible common neural mechanisms of addictions, we investigated cue-induced 'wanting' of 'addictionrelated' reward dissociated from 'liking' aspects. Most studies using visual sexual stimuli do not allow for determination of whether stimuli may represent cues or rewards (Gola, 2016; Gola et al, 2016c) and very rarely permit comparisons to other incentives, making it difficult to interpret results with respect to the IST (Berridge, 2012; Gola et al, 2015, 2016c; Robinson and Berridge, 1993; Robinson et al, 2015).

To investigate, we used an incentive delay task (Figure 1) previously used in studies of gambling disorder (Sescousse et al, 2013). This task has three important properties: it: (1) disentangles cue- and reward-related phases related to anticipation and outcome, respectively; (2) allows measurement of neural and behavioral indicators of 'wanting' (in a cue phase) and 'liking' (in a reward phase); and (3) provides a possibility to compare 'addiction-related' stimuli (in this case, erotic pictures) with another potent reward (monetary gains). As individuals with gambling disorder expressed higher ventral striatal responses to monetary as compared with erotic cues in the cue phase (Sescousse et al, 2013), we hypothesized that men with PPU as compared with those without would demonstrate increased ventral striatal responses for erotic but not for monetary cues. We further hypothesized that the degree of ventral striatal activation to erotic cues in men with PPU would correlate positively with severity of PPU, amount of pornography consumed, and frequency of masturbation. Finally, according to the IST, we hypothesized that 'wanting' in the erotic cue phase would be associated with 'liking' in the reward phase in the CSub group but not in the PPU group, representing a dissociation between 'wanting' and 'liking' in PPU.

\section{MATERIALS AND METHODS}

\section{Participants}

Fifty-seven heterosexual males (age range 18-48 years) participated in the fMRI study. These included 31 men seeking treatment for PPU (meeting criteria of hypersexual disorder; Kafka, 2010) and without other psychiatric diagnoses and 26 CSubs with comparable ages and incomes, also without psychopathology. All subjects were medication-free. Three PPU subjects and two CSubs were excluded from analysis due to extensive head movement $(>7 \mathrm{~mm})$. Characteristics of the remaining $28 \mathrm{PPU}$ subjects and 24 CSubs are presented in Table 1. All participants were financially compensated based on their winnings accumulated during the experimental procedure $(M=184.84 \mathrm{PLN}$; $\mathrm{SD}=21.66$; approximately 46 EUR). Details of recruitment and anonymity procedures are presented in Supplementary Materials. All research procedures were approved by the Ethical Committee of Institute of Psychology, Polish Academy of Science. All subjects provided written informed consent.

\section{Recruitment}

Subjects were recruited among men seeking treatment for PPU in two clinics in Warsaw. After the initial interview, 
a Data collection
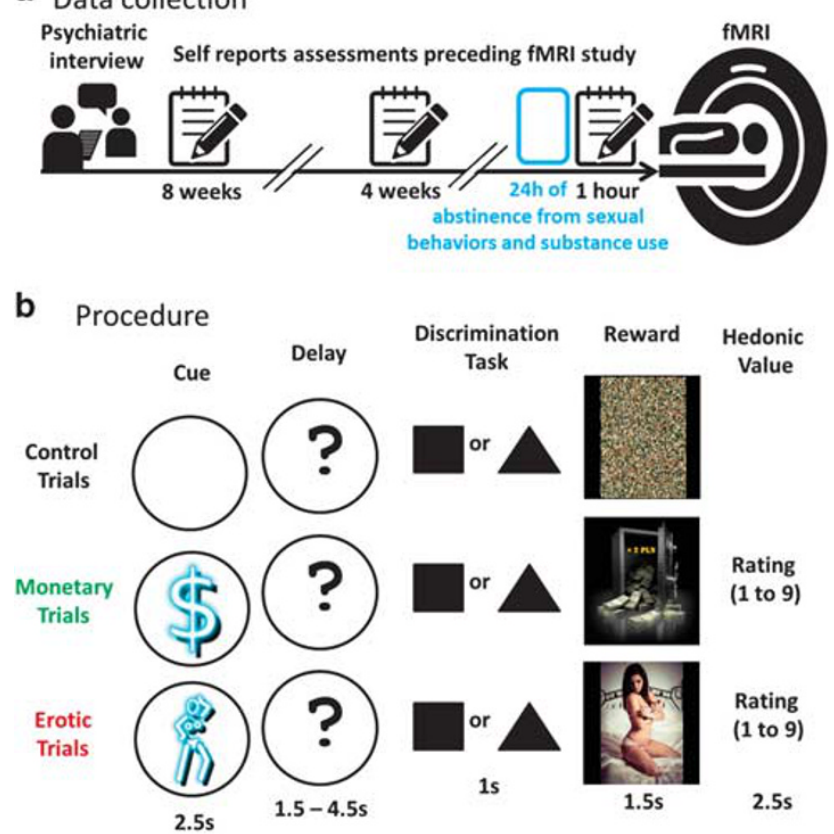

C Types of cues

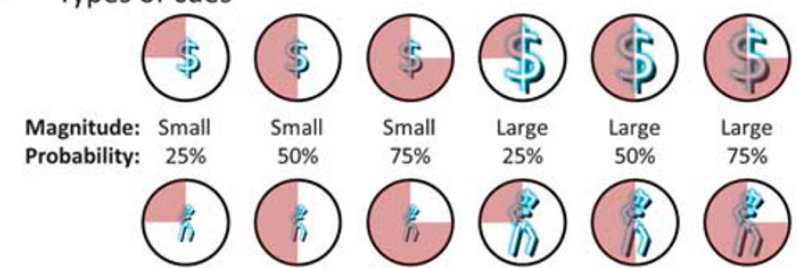

Figure I Data collection and experimental procedure. (a) After psychiatric assessment, subjects who met study criteria (see Patients and Methods section) completed questionnaires assessing self-reported sexual behavior and substance use in the weeks preceding fMRI. (b) Incentive delay task used in the $\mathrm{fMRI}$ session. Subjects first saw a cue informing them about the type (pictogram with a $\$$ or a woman), magnitude (size of pictogram), and probability (pie chart) of an upcoming reward. Examples of all possible cases of cues are presented in Figure Ic. An empty circle was used to signal control trials with a I00\% likelihood of getting no reward (Figure Ib, top). Next, the cue was replaced by a question mark, symbolizing a delay period during which a pseudorandom draw was performed according to the previously displayed probability. Following this anticipation phase, participants had to perform a target discrimination task within I s. The target was either a triangle (left button press required) or a square (right button press required). If subjects answered correctly within $<\mathrm{Is}$, they were then allowed to view the outcome of the pseudorandom draw. RTs were later used as an index of motivation. In rewarded monetary trials (following the cue with pictogram of a \$; Figure 2b, middle), subjects saw a monetary amount displayed on a safe. In rewarded erotic trials (following cue with the pictogram of woman; Figure 2b, bottom), subjects saw an erotic picture. After each reward outcome, subjects had to provide a hedonic rating on a continuous scale (I-do not like it to 9-like it very much). In non-rewarded and control trials, subjects saw a scrambled picture (top). (c) Types of cues. Both monetary and erotic cues provided information about the magnitude and probability of reward. For erotic rewards, a small magnitude was always predictive of pictures of women in lingerie or swimming suits, and a large magnitude was always predictive of explicit pictures of woman in postures inviting sexual activity. For monetary cues, a small magnitude was predictive of gains ranging from I to 3 PLN (approximately $0.25-0.75$ EUR), while a large magnitude was predictive of gains ranging from 6 to 8 PLN (I.5-2 EUR). The probability of obtaining a reward after a correct and fast $(<\mid \mathrm{s})$ response was indicated by a background pie chart representing probabilities of 25,50 , or $75 \%$. All monetary gains were paid to the participants at the end of the experiment. Credits for the sample photo: Lies Thru a Lens, CC BY 2.0. For license terms, see: CC BY 2.0. patients were screened for sexual orientation (inclusion criteria: exclusively or predominantly heterosexual on the Kinsey Scale (Kinsey et al, 1948; Wierzba et al, 2015) and no history of alcohol abuse (scores $<7$ on the Alcohol Use Disorder Identification Test (Saunders et al, 1993) or gambling problems (scores $<3$ on the South Oaks Gambling Screen (Lesieur and Blume, 1987). Patients meeting these criteria and having no contraindication for MRI were screened with the SCID-I (First and Gibbon, 2004) for OCD, ICDs, mood disorders, mania, anxiety disorders, psychotic disorders, history of substance abuse/dependence, and hypersexual disorder according to criteria proposed by Kafka (2010). Only men meeting criteria for hypersexual disorder and none of the other above-mentioned disorders were invited to participate in a 2-month self-assessment study involving completing web-based questionnaires (approximately 8 weeks, 4 weeks, and $1 \mathrm{~h}$ before the fMRI session; Figure 1) and fMRI.

CSubs were recruited through web-based announcements advertising the study as a survey on Internet pornography use (to avoid primary monetary motivations). Among 213 men, we selected 26 heterosexual individuals matched by age (the same year of birth), income $( \pm 15 \%)$ and handedness to each PPU subject. All CSubs had used pornography at least once in the preceding year but had never experienced it as a problematic behavior. All CSubs followed the same procedures as PPU subjects.

\section{Anonymity}

To ensure the anonymity of PPU individuals, we applied a double-blind approach in that the research team in the laboratory had no access to the data gathered by the recruitment and assessment team and thus did not know subjects' group (PPU, CSub) identities. Each subject received an alphanumeric code to maintain anonymity at the data analysis level. We informed subjects about these procedures.

\section{Questionnaire Assessments}

In self-assessments preceding fMRI (Figure 1a), subjects were asked to report their sexual activity during the week (see Table 1). During this phase, we also collected questionnaire measurements for independent verification of screening accuracy and assessment of additional data (as presented in Table 1 and described in detail in the Supplementary Materials).

\section{Incentive Delay Task}

We used the same procedure described in detail in previous studies (Sescousse et al, 2010, 2013), schematized in Figure 1b, and described in Supplementary Materials, with modifications related to the amount of monetary gains. In the original studies, subjects were informed that they would receive a sum of rewards from one randomly chosen experimental block (out of four) (Sescousse et al, 2013). In our study, subjects were told they would receive the exact sum of all monetary gains $(M=184.84$ PLN, which was approximately $5.5 \%$ of monthly salary after taxes). The task permits modeling of events theoretically related to 'wanting' (cues) and 'liking' (rewards). 
Table I Subject Characteristics

\begin{tabular}{|c|c|c|c|}
\hline & Control Sub $(N=24)$, mean $(S D)$ & PPU $(N=28)$, mean $(S D)$ & $p$-Value \\
\hline Age, years & $30.49(7.55)$ & $30.96(6.5 \mathrm{I})$ & $N S^{a}$ \\
\hline Monthly income $e^{b}$ & 3360 PLN $(2264)^{c}$ & 3463 PLN $(2491)^{c}$ & $N S^{a}$ \\
\hline Average pornography consumption per week ${ }^{d}$ & $50.77 \min (42.6)$ & $287.87 \min (258.4)$ & $<0.001$ \\
\hline Longest time of pornography consumption in I day ${ }^{\mathrm{e}}$ & $70.55 \min (52.8)$ & $284.74 \min (321.3)$ & $=0.002$ \\
\hline Average frequency of masturbation per week ${ }^{d}$ & $2.37(1.46)$ & $5.66(3.04)$ & $<0.001$ \\
\hline Sex Addiction Screening Test-Revised (SAST-R) & $2.67(2.12)$ & II.46 (4.95) & $<0.00$ I \\
\hline Brief Pornography Screener (BPS) ${ }^{f}$ & $2.88(3.24)$ & $5.91(2.96)$ & $=0.005$ \\
\hline Sexual Arousability Inventory (SAI) & $83.39(19.27)$ & $88.64(19.89)$ & $N S^{a}$ \\
\hline Obsessive Compulsive Inventory_Revised $(\mathrm{OCl}-\mathrm{R})^{f}$ & $14.13(6.73)$ & $15.77(10.10)$ & $N S^{a}$ \\
\hline UPPS-P Impulsive Behaviour Scale (UPPS-P) ${ }^{f}$ & | $30.73(24.97)$ & $131.87(25.37)$ & $N S^{a}$ \\
\hline Substance use prior to $\mathrm{fMRI}$ session & \multicolumn{3}{|c|}{ Number of subjects using substances within the last: $24 \mathrm{~h} / 2-7$ days/8-90 days/ $>90$ days/never } \\
\hline Tobacco & $3 / 2 / 4 / 10 / 5$ & $3 / 6 / 5 / 11 / 6$ & \\
\hline Alcohol & $0 / 11 / 11 / 2 / 0$ & $0 / 1|/| 1 / 6 / 0$ & \\
\hline Marijuana & $0 / 1 / 3 / 12 / 7$ & $0 / 3 / 5 / 14 / 6$ & \\
\hline
\end{tabular}

References for questionnaires: SAST-R (Carnes et al, 20 I0; Gola et al, 20 I6b); BPS (Kraus et al, 20 I7; see Supplementary Materials); SAI (Gola et al, 20 I 5; Hoon et al, 1976); OCl-R (Foa et al, 2002); UPPS-P (Poprawa, 2016; Whiteside and Lynam, 2003); IVE-I/R (Jaworowska, 20I I); STAl-S/T (Sosnowski and Wrześniewski, I983; Spielberger, 2010).

anon-significant: $p>0.2$.

bincome after taxes.

c PLN is approximately 0.25 EUR. Average monthly income after taxes in Poland in 2014 was 2865 PLN or about 7I6 EUR.

${ }^{\mathrm{d}}$ Averaged across three self-reports about eighth, fourth and last week before the fMRI recording (see Figure la) as all assessments at the 3 time points were highly related to each other within each domain (pornography use measure I and $3: R=0.87$ I; $p<0.0$ I; and masturbation: $R=0.792 ; p<0.0$ I).

eLongest time spent on pornography consumption within $24 \mathrm{~h}$ period (I day).

${ }^{\mathrm{f}}$ These questionnaires were administered during the second assessment (4 weeks before fMRI session). Owing to the time needed for development and validation of Polish language versions, these questionnaires were added during the study and 16 CSubs and 22 PPU subjects completed them. All other questionnaires were administered during the first assessment in all subjects ( 8 weeks before fMRI session). Sexual activity was assessed during all three assessments.

\section{MRI Data Acquisition}

MRI data acquisition was conducted at the Laboratory of Brain Imaging, Neurobiology Center, Nencki Institute of Experimental Biology on a 3-Tesla MR scanner (Siemens Magnetom Trio TIM, Erlangen, Germany) equipped with a 12-channel phased-array head coil. Functional data were acquired using a $\mathrm{T} 2{ }^{\star}$-weighted gradient echo-planar-imaging sequence with the following parameters: repetition time $=2500 \mathrm{~ms}$, echo time $=28 \mathrm{~ms}$, flip angle $=90^{\circ}$, in-plane resolution $=64 \times 64 \mathrm{~mm}$, field of view $=224 \mathrm{~mm}$, and 35 axial slices with $3.5 \mathrm{~mm}$ slice thickness with no gap between slices. Each of the four functional runs consisted of 286 volumes. Field mapping was carried out based on prior methodology (Jezzard and Balaban, 1995) using double-echo FLASH (echo time $1=4.92 \mathrm{~ms}$, echo time $2=7.38 \mathrm{~ms}$ time repetition $=$ $600 \mathrm{~ms}$ ) with the same spatial properties as the functional scans. Detailed anatomical data were acquired with a T1-weighted sequence (repetition time $=2530 \mathrm{~ms}$, echo time $=3.32 \mathrm{~ms}$ ). Head movements were minimized with cushions placed around the participants' heads. Subjects were asked to refrain from any psychoactive substance use and sexual activity during the $24 \mathrm{~h}$ preceding fMRI.

\section{fMRI Analysis}

In line with previous studies (Sescousse et al, 2010, 2013), in the first-level analysis we modeled brain responses during the cue-anticipatory phase and the reward-outcome phase. We modeled separately 13 cue conditions: low/high erotic cue and low/high monetary $\times 3$ probability categories -25 , 50, and 75\% (giving 6 erotic-cue categories and 6 monetarycue categories, as presented in Figure 1c), and one control cue. Brain responses during the reward-outcome phase were modeled as events time-locked to participants' responses in the discrimination task (Figure 1b). Rewards were displayed only after correct responses with 25,50 , or $75 \%$ probabilities (Figure 1c), which gave 5 conditions (erotic reward/lack of erotic reward, monetary reward/lack of monetary reward, lack of reward following control cue) without hedonic ratings. Details of signal preprocessing are provided in Supplementary Material. 

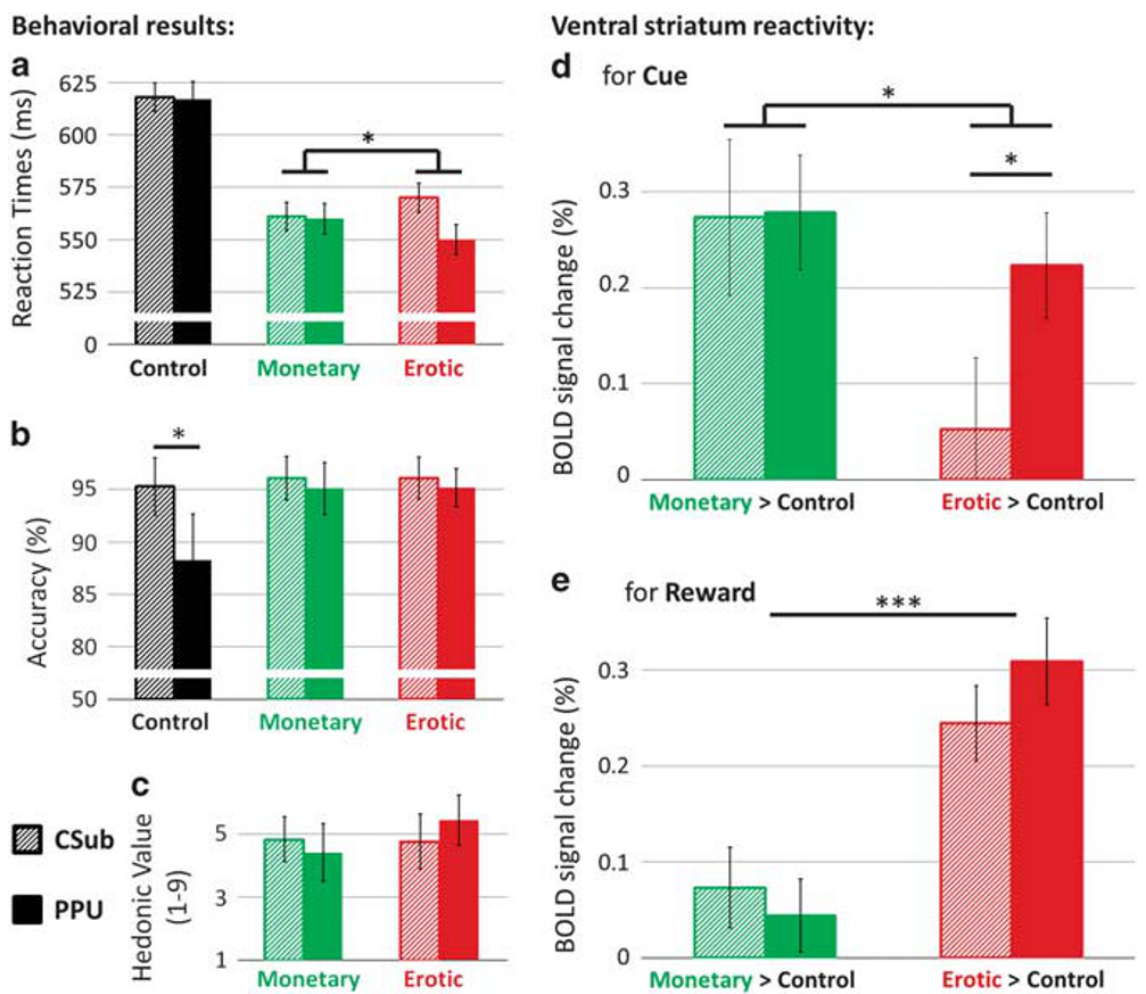

Figure 2 Behavioral and neuroimaging results. (a) Comparison of RTs in the discrimination task (see Figure Ib). (b) Comparison of accuracy. (c) Comparison of hedonic value ratings (see Figure lb). (d) Comparison of BOLD signal change in the ventral striatum for cue presentation (BOLD signal averaged across 2 a priori defined regions of interests in the left and right brain hemisphere: $8-\mathrm{mm}$ spheres centered around: Left: $x=-12, y=10 z=-6$; Right: $x=12, y=10, z=-4$ ). (e) Comparison of BOLD signal response in the ventral striatum for reward presentation. All post hoc tests were carried out with Bonferroni correction for multiple comparisons. Error bars indicates SEM. $* p<0.05$; **** $p<0.00$ I. CSub, control subjects; PPU, problematic pornography users.

\section{Regions of Interests}

We used a striatal ROI defined a priori based on a previous meta-analysis of reward anticipation (Liu et al, 2011); $8 \mathrm{~mm}$ spheres were centered around: Left: $x=-12, y=10 z=-6$; Right: $x=12, y=10, z=-4$ ). To focus on our hypothesis and keep this manuscript concise, we present only analyses using the $a$ priori-defined ROI of the ventral striatum. For control purposes, we also defined an ROI in Heschl's gyrus, where, according to our predictions, no group or condition differences were observed. The ROI was based on the corresponding mask in the AAL atlas taken from the WFU PickAtlas toolbox (version 3.0.5). The percentage of signal change was calculated with the MarsBaR toolbox (http:// marsbar.sourceforge.net). We report significant brain activations within the ROI (Figures 2,3,4, Supplementary Figure S1) that survived family-wise-error (FWE) correction for multiple comparisons using small-volume correction $\left(P_{\text {SVC-FWE }}<0.05\right)$. Owing to the very similar effects for left and right ROIs, we present only results averaged across hemispheres.

\section{Statistical Analysis}

For statistical analyses, IBM SPSS 22 (IBM Released 2013, Armonk, NY: IBM) and MATLAB R2014a (The MathWorks, Natick, MA, USA) were used. Owing to high correlations across time (at the three time points: 8 weeks,
4 weeks, and 1 day before the fMRI) within self-assessed pornography use $(R=0.871 ; p<0.01)$ and masturbation $(R=0.792 ; p<0.01)$, we computed average scores across time for each variable (Figure 1a; Table 1). For testing groupby-trial-type interactions and main effects of group and trial type in BOLD signal from the ROIs, General Linear Models (GLMs) and Fisher's F tests were used (ANOVA with trial type, magnitude of cue, and probability of cue as withinsubject factors and group as a between-subject factor; Figures 2 and 4, Supplementary Figure S1). The same GLMs were used for analysis of RTs (Figures 2 and 3, Supplementary Figure S1 and S2), accuracy, and hedonic value (Figure 2,Supplementary Figure S2). All post hoc comparisons were conducted with Bonferroni-Holms correction. Correlations between BOLD signal and measures of symptoms were computed only for measures significantly differentiating PPU subjects from CSubs (SAST-R, BPS, amount of pornography use, and masturbation). Owing to the discrete thresholding of SAST-R scores and skewedness of distributions of the three other measures, Spearman's Rho was used to compute covariance.

\section{RESULTS}

\section{Between-Group Differences}

Men seeking treatment for PPU and CSubs did not differ in age, income, impulsivity, or compulsivity (Table 1). 


\section{Magnitude of cue}
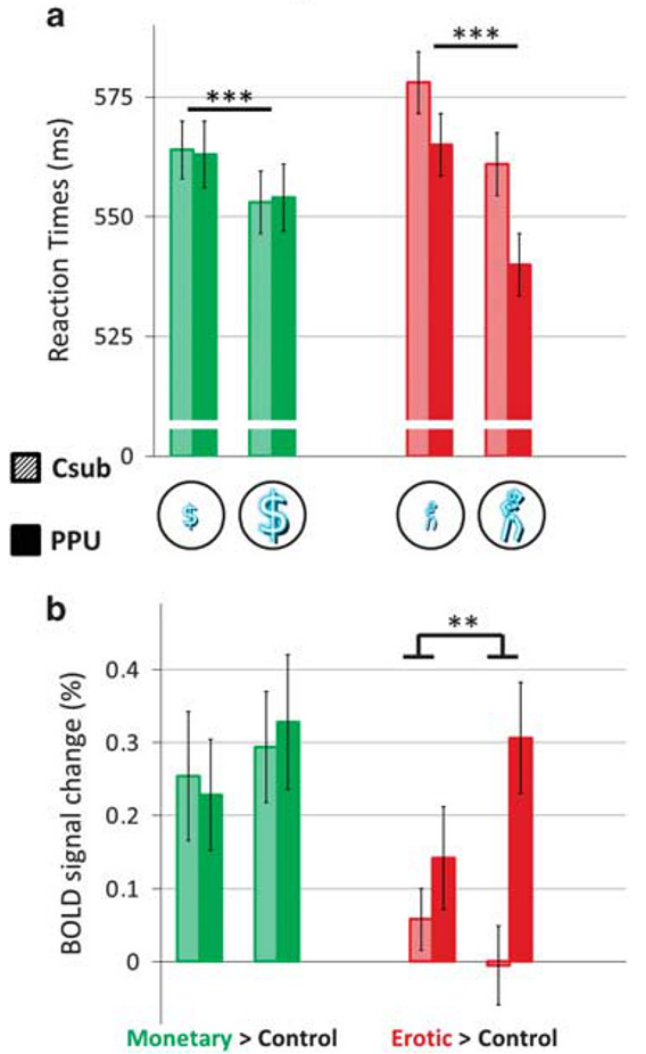

Figure 3 Between-group differences in ventral striatal reactivity for cues predicting small and large magnitudes of monetary (green) and erotic (red) rewards. (a) Comparison of RTs for cues predictive of small and large rewards. (b) Comparison of BOLD signal response in the ventral striatum (the same ROls as in Figure 2) for presentations of cues with different magnitudes. Error bars indicates SEM. $* * * 2<0.01$; ${ }^{*} * * * 0.001$. CSub, control subjects; PPU, problematic pornography users.

Although no subjects met criteria for anxiety disorders, men with PPU as compared with CSubs exhibited higher trait anxiety $(t(50)=2.37 ; p=0.022$; STAI-T). No difference in self-declared sexual arousability (SAI) was observed; however, men with PPU as compared with CSubs showed higher sexual arousability for compensatory activities such as pornography use and masturbation on the corresponding SAI subscale $(t(46)=3.348 ; p=0.002)$.

As anticipated, men with PPU as compared with CSubs demonstrated higher scores on the Sex Addiction Screening Test-Revised (SAST-R; $t(50)=8.539 ; p<0.001$ ) and Brief Pornography Screening Test (BPS; $t(36)=2.998 ; p=0.005$ ) and reported more pornography use $(t(50)=3.776$; $p<0.001)$ and more frequent masturbation $(t(50)=5.042$; $p<0.001)$ during the weeks preceding fMRI.

Both groups had similar accuracy for monetary and erotic trials (Figure $2 \mathrm{~b}$ ) and obtained similar amounts of monetary wins (CSubs: $M=187.41$ PLN; $S D=22.83$, PPU subjects: $M=182.14$ PLN; SD = 20.56).

\section{Behavioral Results}

We analyzed RTs, accuracy, and hedonic value ratings. A significant group-by-cue-type interaction on RTs was observed $(\mathrm{F}(1,50)=5.112 ; p=0.028)$. The shortest RTs were observed in men with PPU during erotic trials (Figure 2a). Main effects of group $(\mathrm{F}(1,50)=0.223 ; p=0.639)$ or cue type $(\mathrm{F}(1,50)=0.390 ; p=0.535)$ were insignificant. We observed a significant main effect of cue magnitude on RTs $(F(1,50)=$ 42.152; $p<0.000001$; Figure 3a). RTs in trials with cues predicting large rewards were shorter. We found a significant interaction between the type and magnitude of cue $(\mathrm{F}(1,50)=7.416 ; p=0.009)$. As there were no interactions of probability and group both in $\mathrm{RTs}(\mathrm{F}(2,50)=1.132$; $p=0.331)$ and BOLD response $(\mathrm{F}(2,50)=2.046 ; p=0.135)$, we present these results in Supplementary Material (Supplementary Figure S1). There was also a main effect of cue probability on $\mathrm{RTs}(\mathrm{F}(2,50)=20.671 ; p<0.000001)$, but no group-by-probability interaction $(\mathrm{F}(2,50)=1.132$; $p=0.331$ ); thus, we present these results in Supplementary Material (Supplementary Figure S1).

Analysis of accuracy revealed interesting results. Although there was no group $(\mathrm{F}(1,50)=0.619 ; p=0.435)$ or group-bycue-type interaction $(\mathrm{F}(1,50)=0.002 ; p=0.969)$ in accuracy for reward-related cues (monetary and erotic), there was a trend toward an effect of group-by-cue-type interaction taking into account non-rewarded control cues $(\mathrm{F}(2,100)=$ 3.014; $p=0.054$ ). This pattern appears driven by decreased accuracy of PPU men (compared with CSubs) on control (non-rewarded) trials $(t(50)=2.084 ; p=0.045)$. This result shows that, while PPU and CSubs have comparable accuracy in trials providing chance for a reward (monetary and erotic), PPU men demonstrate decreased accuracy in non-rewarded (control) trials (Figure $2 \mathrm{~b}$ ).

No differences were observed in hedonic value ratings $(\mathrm{F}(1,50)=0.187 ; \quad p=0.667 ;$ Figure $2 \mathrm{c})$, which may be considered declarative measure of liking.

\section{Neuroimaging Results}

Similar to RTs, cue-related reactivity of the ventral striatum demonstrated a group-by-cue-type interaction $(\mathrm{F}(1,50)=$ 6.886; $p=0.011$; Figure 2d). Men with PPU and CSubs differed significantly in reactivity for erotic $(t(50)=2.624$; $p=0.011)$ but not monetary $(t(50)=0.047 ; p=0.963)$ cues. During the reward-processing phase, a main effect of cue type was observed $(\mathrm{F}(1,50)=44.308 ; p<0.001)$, but no betweengroup differences were observed $(\mathrm{F}(1,50)=0.061 ; p=0.806)$. Also no group-by-reward-type interaction $(\mathrm{F}(1,50)=0.2 .054$; $p=0.158$ ) was observed. These results indicate that PPU men and CSubs differ during the cue phase but demonstrate similar ventral striatal reactivity in the reward phase, with results showing a significant three-way group-by-cue-type-by-processing-phase (cue vs reward) interaction $(\mathrm{F}(1,50)=5.438$; $p=0.024)$. The results are consistent with a dissociation between brain measures of 'wanting' and 'liking' of erotic stimuli in PPU subjects but not in CSubs.

We also observed a significant group-by-cue-type-bymagnitude interaction in ventral striatal BOLD signal change during the cue phase $(\mathrm{F}(1,50)=5.432 ; p=0.024)$. Although for monetary cues, there was no group-by-magnitude interaction $(\mathrm{F}(1,50)=0.613 ; p=0.482)$ or main effect of group $(\mathrm{F}(1,50)=0.002 ; p=0.963)$, the group-by-magnitude interaction $(\mathrm{F}(1,50)=8.273 ; p=0.007)$ and main effect of group $(\mathrm{F}(1,50)=5.914 ; p=0.019)$ were significant for erotic cues. The findings indicate that stronger BOLD response in 

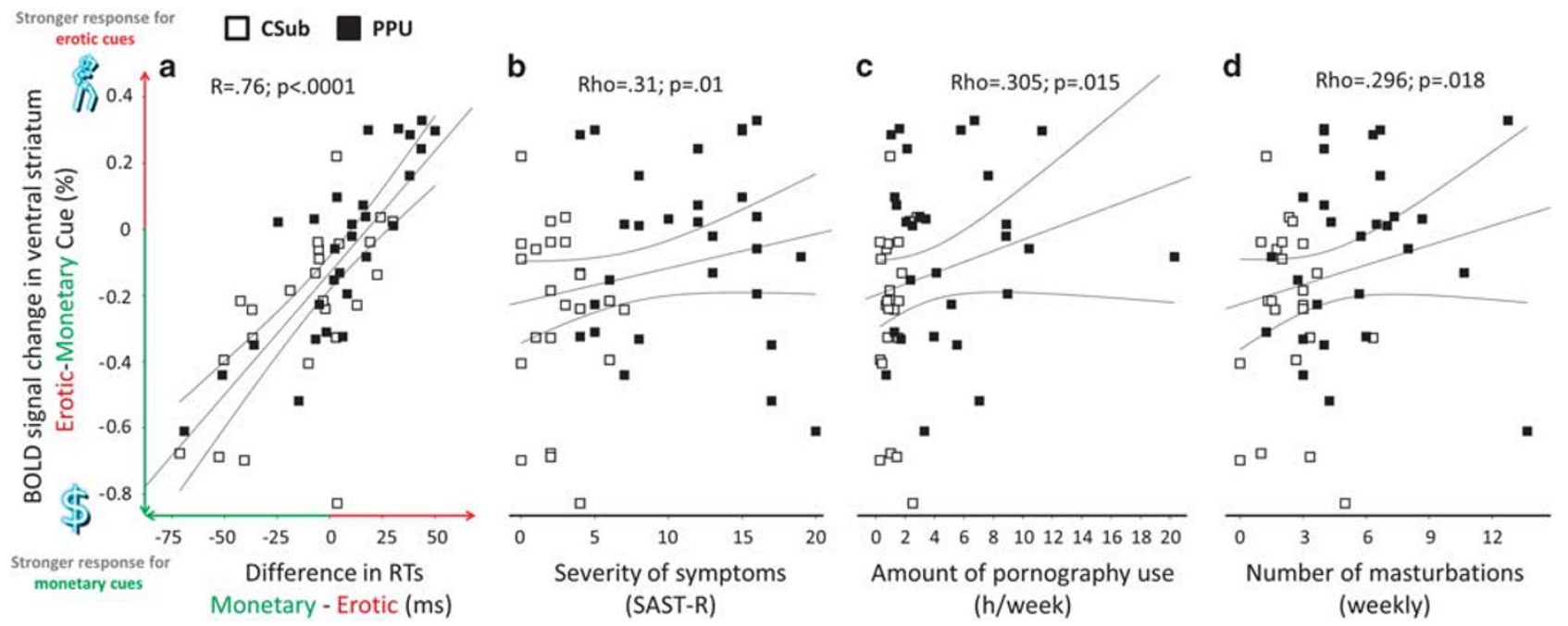

Figure 4 Correlations of ventral striatal cue-reactivity with amount of pornography use, frequency of masturbation, and clinical features of PPU. The correlations between differential striatal reactivity to monetary vs erotic cues and (a) relative motivation index measured as difference between RTs for monetary-erotic trials; (b) severity of CSB measured by the Sexual Addictions Screening Test-Revised (20 points scale, which was not used at recruitment phase); (c) average amount of pornography consumption per week, and (d) frequency of masturbation per week. Error lines depicts $95 \%$ confidence intervals. Bonferroni-Holms correction was used for multiple comparisons. CSub, control subjects; PPU, problematic pornography users.

the ventral striatum for erotic cues among PPU men (compared with CSubs) is modulated by magnitude of erotic cue (Figure 3b). The whole-brain BOLD response for the second-level contrast $\mathrm{PPU}_{(\text {high }>\text { low magnitude) }}>$ CSubs $_{\text {(high }>\text { low magnitude) }}$ is presented in Supplementary Figure S3. We also observed a main effect of cue probability on ventral striatal BOLD signal change $(\mathrm{F}(2,50)=5.379$; $p=0.006)$. As there were no group-by-probability effects $(\mathrm{F}(2,50)=2.046 ; p=0.135)$, we present these results in Supplementary Materials (Supplementary Figure S1).

\section{Relationships Between Behavioral and Neuroimaging Results and Clinical Features of PPU}

In line with previous work (Sescousse et al, 2013, 2015), we computed for each subject the differential reactivity to monetary $v s$ erotic cues by subtracting the corresponding striatal BOLD responses. We also calculated a relativemotivation index measured as the difference in mean RTs for monetary and erotic trials. The brain-behavior correlation between these two measures was strongly significant $(R=0.76 ; p<0.0001$, Figure $4 \mathrm{a})$. Next, we examined how individual differences in ventral striatal reactivity for erotic $v s$ monetary cues related to four measures differentiating both groups (Table 1): severity of CSB symptoms measured with the SAST-R $(\mathrm{Rho}=0.31 ; p=0.01$; Figure $4 \mathrm{~b})$, pornography craving measured with the BPS $(\mathrm{Rho}=0.264$; $p=0.055$ ), amount of pornography consumption (Rho= $0.305 ; p=0.015$; Figure $4 c$ ), and number of masturbations per week $($ Rho $=0.296 ; p=0.018$; Figure $4 d)$. BonferroniHolms correction for multiple comparisons was used. We also examined how individual differences in ventral striatal reactivity for erotic $v s$ monetary cues related to masturbation (Rho $=0.313 ; p=0.034)$ and amount of pornography consumption (Rho $=0.47 ; p=0.054)$ only among PPU subjects.

In the next step, we checked whether an analogous index of liking would be related to behavioral measures. For this purpose, we calculated an individual relative-liking index measured as differences in ventral striatal reactivity for erotic and monetary rewards. We related this index to individual differences in ratings of rewards' hedonic values and the same four measures differentiating both groups as above. None of the correlations were significant.

\section{DISCUSSION}

Our results, in line with the Incentive Salience Theory (IST; Berridge, 2012; Gola et al, 2016c; Robinson and Berridge, 1993; Robinson et al, 2015), indicate that men seeking treatment for PPU when compared with CSubs show increased ventral striatal reactivity for cues predicting erotic pictures (but not for cues predicting monetary gains). Such increased striatal reactivity for cues predicting erotic content is followed by higher motivation (reflected in shorter RTs) to view erotic rewards (Figures 2a, 2d and 4a). Consistent with the IST (Robinson and Berridge, 1993; Robinson et al, 2015), these results suggest increased 'wanting' evoked specifically by an initially neutral cue predictive for erotic rewards. Also as predicted by the IST, a neural indicator of 'wanting' (BOLD response in the ventral striatum) is dissociated from measures of 'liking' among PPU men but not CSubs, and this was reflected in three-way interactions between incentives (monetary vs erotic), group (CSubs vs PPU), and experimental phase (cue vs reward). In other words, subjects who seek treatment for PPU expressed higher motivational behavior for cues predictive of erotic content. This motivated behavior ('wanting', probably related to the expectation of highly rewarding value of pornography) is dissociated from actual 'liking': PPU subjects did not differ from CSubs in BOLD response for erotic pictures (reward phase) or hedonic values ratings (Figures $2 \mathrm{c}$ and $2 \mathrm{e}$ ). Moreover, the differential striatal reactivity to erotic $v s$ monetary cues (but not rewards) was related not only to indicators of motivated 
behaviors during the study (RTs; Figure 4a) but also to the severity of CSB (measured with the SAST-R; Figure 4b), amount of pornography consumption, and frequency of masturbation (Figures $4 \mathrm{c}$ and $4 \mathrm{~d}$ ) reported during the 2 months preceding fMRI.

This pattern of increased cue-related 'wanting' dissociated from reward-related 'liking' resembles findings in addictions (Robinson et al, 2015; Sescousse et al, 2013). Specific cues (predictive for addiction-related rewards) evoke activations of brain-reward systems associated with striatal responses (Flagel et al, 2011; Oei et al, 2012; Robinson and Berridge, 1993; Smith et al, 2011) and motivations to approach rewards, but experienced hedonic value (Berridge, 2012; Robinson et al, 2015) or striatal response for reward (Flagel et al, 2011) are not proportional to ones evoked by the preceding cue. These findings are consistent with an impaired mechanism of updating cue-related predictions about expected values of erotic stimuli, similar to mechanisms proposed for substance-use disorders (Parvaz et al, 2015; Tanabe et al, 2013), although this possibility warrants direct investigation. Given the role of the ventral striatum in reward anticipation (Balodis and Potenza, 2015), initially neutral stimuli (akin to cues introduced in our experimental procedure) may become for men with PPU powerful incentives under the circumstances of pairing them with erotic images. Our results show that individuals with PPU are much more sensitive (then CSubs) for cues signaling erotic rewards (Figure $2 \mathrm{~d}$ ) and the magnitude of the expected erotic reward further modulates the ventral striatal reactivity in men with PPU, which does not happen among CSubs (Figure 4). These results are in line with recent studies showing stronger effects of conditioning for cues predicting explicit sexual content among individuals with CSB compared with CSubs (Banca et al, 2016; Klucken et al, 2016). Along with these and other studies (Gola et al, 2016c; Mechelmans et al, 2014), our results suggest that conditioned stimuli associated with erotic rewards may overshadow motivational values of alternate sources of reward in men with PPU, eventually leading to PPU. However, longitudinal studies are needed to examine this hypothesis.

Our results show that PPU is related to alterations in motivational processes. Besides increased striatal response for cues predicting erotic rewards and accompanying increases in motivated behaviors (RTs to erotic cues), men with PPU also exhibited a decrease in motivated behaviors for non-rewarded trials (lower accuracy, Figure 2b) when compared with CSubs. This finding raises questions whether men with PPU may have more generalized impairments of reward processing, in line with a reward deficiency syndrome theory (Comings and Blum, 2000), which would predict decreased striatal reactivity and accompanying hedonic values for both types of rewards (erotic and monetary) in the reward phase. Here we show that this is not the case; men with and without PPU do not differ in striatal reactivity and hedonic values either for erotic or monetary rewards. The key difference between these two groups is in striatal reactivity (and accompanying behavioral reactions) in response for cues.

In our study, we have made the assumption that RTs (Figure 4a) directly reflect motivation. Such a coupling has been assumed in several previous studies (Clithero et al, 2011; Sescousse et al, 2015) and is grounded in computational work linking motivation and vigor via dopamine (Niv et al, 2007). Also we think that two aspects of our design help narrowing the interpretation of RTs in terms of motivation rather than response vigor. The first is that the motor component of our task was not a simple target detection task but a discrimination task with two possible button responses, precluding the interpretation of differences in RTs in terms of motor preparation. In addition, the use of the monetary cue condition can be regarded as a 'baseline' condition controlling for group differences in response vigor or motor activation. Yet, in the absence of self-report 'wanting' ratings, we cannot rule out the potential influence of motor activation on RTs. Complementary procedures such as preference tasks could be used in future studies to refine the interpretation of the current results. Additionally, given possible carry-over effects, we cannot entirely exclude the potential influence of rewards on subsequent cue processing, although we believe that our counter-balanced task design helps to mitigate against this possibility.

Despite the above-mentioned limitations, our findings indicate that increased cue-reactivity among men with PPU is not a general dysfunction but is related to cues predictive of erotic but not monetary rewards. This selective mechanism of increased reactivity for erotic but not monetary cues among men with PPU speaks in favor of the IST (Robinson and Berridge, 1993) rather than more generalize impairments of reward processing proposed in example by theoretical frameworks, such as the reward deficiency syndrome (Comings and Blum, 2000). Lack of betweengroup differences in compulsivity (measured with the OCI$\mathrm{R}$ ) and in responses to monetary cues, speaks also against conceptualization within an OCD framework (Kor et al, 2013), as OCD patients present decreased striatal BOLD response for cues predictive for monetary gains when compared with CSubs (Figee et al, 2011). However, it is important to note that we were excluding all subjects with comorbid psychiatric disorders (approximately 50\% of treatment-seeking individuals were excluded for this reason during the initial screening procedure), so our conclusion about a lack of generalized reward processing impairment may not generalize to men with PPU and comorbid disorders. Despite this limitation, the exclusion of individuals with PPU and co-occurring psychiatric disorders permitted for a more focused study on mechanisms underlying PPU and excludes possible effects of psychopathology. Additional limitations include the exclusion of women, and future studies should examine the extent to which the findings extend to women with PPU. Additionally, future studies should examine how neurobiological and clinical measures might relate to treatment outcomes for individuals with PPU.

\section{CONCLUSIONS}

Men with PPU showed increased activation of the ventral striatum specifically for cues predicting erotic but not monetary rewards. In PPU subjects, this brain activation was accompanied by measures suggesting increased behavioral motivation to view erotic images (higher 'wanting'). Ventral striatal reactivity for cues signaling erotic pictures (but not for erotic pictures per se) was significantly related to 
severity of CSB, amount of pornography use per week, and frequency of masturbation. The findings suggest similarities between PPU and addictions and an important role for learned cues in PPU. Identifying PPU-related triggers and targeting the dissociation of learned cues from problematic behaviors may be useful in the treatment of PPU. Future studies should examine specific treatments, as well as determine the prevalence and clinical correlates of PPU, and identify predisposing factors for PPU.

\section{FUNDING AND DISCLOSURE}

This study was supported by the Polish National Science Centre, OPUS grant number 2014/15/B/HS6/03792 (to MG). MG was also supported by the Polish Ministry of Science scholarships (1057/MOB/2013/0 and 469/STYP/10/2015), scholarship Start of Foundation for Polish Science and scholarship of The Kosciuszko Fundation. GS was supported by a Veni grant from The Netherlands Research Organization (NWO). MNP is supported by the National Center on Addiction and Substance Abuse and the National Center for Responsible Gaming. The views presented in the article do not necessarily reflect those of the funding agencies and rather reflect those of the authors. MNP has consulted for and advised Ironwood, Lundbeck, INSYS, Shire, RiverMend Health, Opiant/Lakelight Therapuetics, and Jazz Pharmaceuticals; has received research support from Mohegan Sun Casino, the National Center for Responsible Gaming, and Pfizer; has participated in surveys, mailings or telephone consultations related to drug addiction, impulse-control disorders, or other health topics; has consulted for gambling and legal entities on issues related to impulsecontrol and addictive disorders; provides clinical care in the Connecticut Department of Mental Health and Addiction Services Problem Gambling Services Program; has performed grant reviews for the National Institutes of Health and other agencies; has edited journals or journal sections; has given academic lectures in grand rounds, CME events, and other clinical or scientific venues; and has generated books or book chapters for publishers of mental health texts. MLS has consulted for Eli Lilly, PPF Hasco, Lundbeck, National Bureau for Drug Prevention (Poland), Pfizer, Polpharma and Verco; has received research support from the Polish Ministry of Science and the European Society for Sexual Medicine. MLS provides medical care in the III Department of Psychiatry, Institute of Psychiatry and Neurology, Warsaw, Poland, and in the Lew-Starowicz Therapy Centre. MLS is the Editor of Sexological Review journal, has given academic lectures in CME events and generated books or book chapters for publishers of mental health texts. The other authors declare no conflict of interest.

\section{ACKNOWLEDGMENTS}

We are grateful to all participants who agreed to be involved in this study; M Skorko and the VR Lab (http://vrlab.edu.pl/) for the possibility of using the GEx platform to collect the questionnaire data; and M Wilk, P Winkielman, J Rapela, E Kowalewska, M Bielecki, P Holas, Ł Okruszek, Ł Głowacki, W Ciemniewski, and D Baran for help and comments. This project was realized with the aid of CePT research infrastructure purchased with funds from the European Regional Development Fund as part of the Innovative Economy Operational Programme, 2007-2013.

\section{AUTHOR CONTRIBUTIONS}

MG, GS, and AM designed the project. MG, GS, and BK prepared experimental procedures. MG and ML-S recruited subjects and collected clinical data. $\mathrm{M}$ Wordecha conducted the experiments. MG, M Wordecha, BK, M Wypych, and AM performed the statistical analysis. MG, GS, MNP, and M Wordecha analyzed the findings. MG, GS, and MNP wrote the manuscript.

\section{REFERENCES}

American Psychiatric Association (2013). Diagnostic and Statistical Manual of Mental Disorders (DSM-5 ${ }^{\circ}$ ). American Psychiatric Association Publishing: Arlington, VA, USA.

Balodis IM, Potenza MN (2015). Anticipatory reward processing in addicted populations: a focus on the monetary incentive delay task. Biol Psychiatry 77: 434-444.

Banca P, Morris LS, Mitchell S, Harrison NA, Potenza MN, Voon V (2016). Novelty, conditioning and attentional bias to sexual rewards. J Psychiatr Res 72: 91-101.

Berridge KC (2012). From prediction error to incentive salience: mesolimbic computation of reward motivation. Eur J Neurosci 35: 1124-1143.

Bostwick JM, Bucci JA (2008). Internet sex addiction treated with naltrexone. Mayo Clin Proc 83: 226-230.

Brand M, Snagowski J, Laier C, Maderwald S (2016). Ventral striatum activity when watching preferred pornographic pictures is correlated with symptoms of Internet pornography addiction. Neuroimage 129: 224-232.

Carnes P, Green B, Carnes S (2010). The same yet different: refocusing the Sexual Addiction Screening Test (SAST) to reflect orientation and gender. Sex Addict Compulsivity 17: 17-30.

Clithero JA, Reeck C, Carter RM, Smith DV, Huettel SA (2011). Nucleus accumbens mediates relative motivation for rewards in the absence of choice. Front Hum Neurosci 5: 87.

Comings DE, Blum K (2000). Reward deficiency syndrome: genetic aspects of behavioral disorders. Prog Brain Res 126: 325-341.

Figee M, Vink M, de Geus F, Vulink N, Veltman DJ, Westenberg H et al (2011). Dysfunctional reward circuitry in obsessivecompulsive disorder. Biol Psychiatry 69: 867-874.

First M, Gibbon M (2004). The Structured Clinical Interview for DSM-IV Axis I Disorders (SCID-I) and the Structured Clinical Interview for DSM-IV Axis II Disorders (SCID-II) < http:// psycnet.apa.org/psycinfo/2004-12821-011>.

Flagel SB, Clark JJ, Robinson TE, Mayo L, Czuj A, Willuhn I et al (2011). A selective role for dopamine in stimulus-reward learning. Nature 469: 53-57.

Foa E, Huppert J, Leiberg S, Langner R, Kichic R, Hajcak G et al (2002). The Obsessive-Compulsive Inventory: development and validation of a short version. Psychol Assess 14: 485-496.

Gola M (2016). Decreased LPP for sexual images in problematic pornography users may be consistent with addiction models. Everything depends on the model. (Commentary on Prause, Steele, Staley, Sabatinelli, \& Hajcak, 2015). Biol Psychol 120: 156-158.

Gola M, Miyakoshi M, Sescousse G (2015). Sex, impulsivity and anxiety: interplay between ventral striatum and amygdala reactivity in problematic sexual behaviors. J Neurosci 35: 1522715229. 
Gola M, Kowalewska E, Wierzba M, Wordecha M, Marchewka A (2015). Polish adaptation of the Sexual Arousability Inventory SAI-PL and validation for males. Psychiatria 12: 245-254.

Gola M, Lewczuk K, Skorko M (2016a). What matters: quantity or quality of pornography use? Psychological and behavioral factors of seeking treatment for problematic pornography use. J Sex Med 13: 815-824.

Gola M, Potenza MN (2016). Paroxetine treatment of problematic pornography use: a case series. J Behav Addict 5: 529-532.

Gola M, Skorko M, Kowalewska E, Kołodziej A, Sikora M, Wodyk $\mathrm{M}$ et al (2016b). Polish adaptation of Sexual Addiction Screening Test - Revised. Polish Psychiatry 41: 1-40.

Gola M, Wordecha M, Marchewka A, Sescousse G (2016c). Visual sexual stimuli-cue or reward? A perspective for interpreting brain imaging findings on human sexual behaviors. Front Hum Neurosci 10: 402.

Hald GM (2006). Gender differences in pornography consumption among young heterosexual Danish adults. Arch Sex Behav 35: 577-585.

Holden C (2001). Behavioral ' addictions: do they exist? Science 294: 980-982.

Hoon EF, Joon PW, Wincze JP (1976). An inventory for the measurement of female sexual arousability: the SAI. Arch Sex Behav 5: 269-274.

Jaworowska A (2011). IVE-Kwestionariusz Impulsywności. Pracownia Testów Psychologicznych, Warszawa, Poland.

Jezzard P, Balaban RS (1995). Correction for geometric distortion in echo planar images from B0 field variations. Magn Reson Med 34: 65-73.

Kafka MP (2010). Hypersexual disorder: a proposed diagnosis for DSM-V. Arch Sex Behav 39: 377-400.

Kafka MP (2014). What happened to hypersexual disorder? Arch Sex Behav 43: 1259-1261.

Kinsey A, Pomeroy W, Martin C (1948). Sexual behavior in the human male < http://www.ncbi.nlm.nih.gov/pmc/articles/PMC 2092220/pdf/brmedj03707-0002.pdf > .

Klucken T, Wehrum-Osinsky S, Schweckendiek J, Kruse O, Stark R (2016). Altered appetitive conditioning and neural connectivity in subjects with compulsive sexual behavior. J Sex Med 13: 627-636.

Kor A, Fogel YA, Reid RC, Potenza MN (2013). Should hypersexual disorder be classified as an addiction? Sex Addict Compulsivity 20: $27-47$.

Kraus SW, Gola M, Kowalewska E, Lew-Starowicz M, Hoff RA, Porter E (2017). Brief Pornography Screener: A comparison of US and Polish pornography users. J Behav Addic 6: 27.

Kraus SW, Meshberg-Cohen S, Martino S, Quinones L, Potenza M (2015). Treatment of compulsive pornography use with naltrexone: a case report. Am Psychiatry J 172: 1260-1261.

Kraus SW, Voon V, Potenza MN (2016). Should compulsive sexual behavior be considered an addiction? Addiction 111: 2097-2106.

Krueger R (2016). Diagnosis of hypersexual or compulsive sexual behavior can be made using ICD-10 and DSM-5 despite rejection of this diagnosis by the American Psychiatric Association. Addiction 111: 2110-2111.

Kühn S, Gallinat J (2014). Brain structure and functional connectivity associated with pornography consumption: the brain on porn. JAMA Psychiatry 71: 827-834.

Lesieur HR, Blume SB (1987). The South Oaks Gambling Screen (SOGS): a new instrument for the identification of pathological gamblers. Am J Psychiatry 144: 1184-1188.

Liu X, Hairston J, Schrier M, Fan J (2011). Common and distinct networks underlying reward valence and processing stages: a meta-analysis of functional neuroimaging studies. Neurosci Biobehav Rev 35: 1219-1236.

Luscombe B (2016). Porn and the threat to virility. Time 187: 40-47. Maisel NC, Blodgett JC, Wilbourne PL, Humphreys K, Finney JW (2013). Meta-analysis of naltrexone and acamprosate for treating alcohol use disorders: when are these medications most helpful? Addiction 108: 275-293.

Mechelmans DJ, Irvine M, Banca P, Porter L, Mitchell S, Mole TB et al (2014). Enhanced attentional bias towards sexually explicit cues in individuals with and without compulsive sexual behaviours. PLoS ONE 9: e105476.

Niv Y, Daw ND, Joel D, Dayan P (2007). Tonic dopamine: opportunity costs and the control of response vigor. Psychopharmacology (Berl) 191: 507-520.

Oei NYL, Rombouts SA, Soeter RP, Gerven JM, van, Both S (2012). Dopamine modulates reward system activity during subconscious processing of sexual stimuli. Neuropsychopharmacology 37: 1729-1737.

Opinium Research (2014). 500 Online Interviews Amongst UK Adults Aged 18. Institute for Public Policy Research: UK.

Parvaz MA, Konova AB, Proudfit GH, Dunning JP, Malaker P, Moeller SJ et al (2015). Impaired neural response to negative prediction errors in cocaine addiction. J Neurosci 35: 1872-1879.

Poprawa R (2016). Polska adaptacja UPPS-P Skali Impulsywnego Zachowania oraz jej znaczenie w predykcji wybranych eksternalizowanych problemów i zaburzeń. Przegląd Psychologiczny 59: 95-116.

Reid RC, Carpenter BN, Hook JN, Garos S, Manning JC, Gilliland R et al (2012). Report of findings in a DSM-5 field trial for hypersexual disorder. J Sex Med 9: 2868-2877.

Robinson M, Fischer A, Ahuja A, Lesser E, Maniates H (2015). Roles of "wanting" and "liking" in motivating behavior: gambling, food, and drug addictions. Curr Top Behav Neurosci: 27: 105-136.

Robinson TE, Berridge KC (1993). The neural basis of drug craving: an incentive-sensitization theory of addiction. Brain Res Brain Res Rev 18: 247-291.

Sabina C, Wolak J, Finkelhor D (2008). The nature and dynamics of internet pornography exposure for youth. Cyberpsychol Behav 11: 691-693.

Saunders JB, Aasland OG, Babor TF, Fuente JR, de la, Grant M (1993). Development of the Alcohol Use Disorders Identification Test (AUDIT): WHO Collaborative Project on Early Detection of Persons with Harmful Alcohol Consumption-II. Addiction 88: 791-804.

Sescousse G, Barbalat G, Domenech P, Dreher J-C (2013). Imbalance in the sensitivity to different types of rewards in pathological gambling. Brain 136: 2527-2538.

Sescousse G, Li Y, Dreher J-C (2015). A common currency for the computation of motivational values in the human striatum. Soc Cogn Affect Neurosci 10: 467-473.

Sescousse G, Redouté J, Dreher J-C (2010). The architecture of reward value coding in the human orbitofrontal cortex. J Neurosci 30: 13095-13104.

Smith KS, Berridge KC, Aldridge JW (2011). Disentangling pleasure from incentive salience and learning signals in brain reward circuitry. Proc Natl Acad Sci USA 108: E255-E264.

Smith PH, Potenza MN, Mazure CM, McKee SA, Park CL, Hoff RA (2014). Compulsive sexual behavior among male military veterans: prevalence and associated clinical factors. J Behav Addict 3: 214-222.

Sosnowski T, Wrześniewski K (1983). Polska adaptacja inwentarza STAI do badania stanu i cechy lęku. Przegląd Psychologiczny 393-412.

Spielberger C (2010). State-Trait Anxiety Inventory <http:// onlinelibrary.wiley.com/doi/10.1002/9780470479216.corpsy0943/ full $>$.

Stein DJ, Andersen EW, Tonnoir B, Fineberg N (2007). Escitalopram in obsessive-compulsive disorder: a randomized, placebocontrolled, paroxetine-referenced, fixed-dose, 24-week study. Curr Med Res Opin 23: 701-711.

Tanabe J, Reynolds J, Krmpotich T, Claus E, Thompson LL, Du YP et al (2013). Reduced neural tracking of prediction error in 
substance-dependent individuals. Am J Psychiatry 170: 1356-1363.

Thompson AC, Zapata A, Justice JB, Vaughan RA, Sharpe LG, Shippenberg TS (2000). Kappa-opioid receptor activation modifies dopamine uptake in the nucleus accumbens and opposes the effects of cocaine. J Neurosci 20: 9333-9340.

Voon V, Mole TB, Banca P, Porter L, Morris L, Mitchell S et al (2014). Neural correlates of sexual cue reactivity in individuals with and without compulsive sexual behaviours. PLOS ONE 9: e102419.
Whiteside SP, Lynam DR (2003). Understanding the role of impulsivity and externalizing psychopathology in alcohol abuse: application of the UPPS impulsive behavior scale. Exp Clin Psychopharmacol 11: 210-217.

Wierzba M, Riegel M, Pucz A, Leśniewska Z, Dragan WŁ, Gola M et al (2015). Erotic subset for the Nencki Affective Picture System (NAPS ERO): cross-sexual comparison study. Front Psychol 6: 1336.

Yip SW, Potenza MN (2014). Treatment of gambling disorders. Curr Treat Options Psychiatry 1: 189-203.

Supplementary Information accompanies the paper on the Neuropsychopharmacology website (http://www.nature.com/npp) 